\title{
Incidence and risk factors associated with postoperative delirium following primary elective total hip arthroplasty: a retrospective nationwide inpatient sample database study
}

\author{
Qinfeng Yang ${ }^{\dagger}$, Jian Wang ${ }^{\dagger}$, Xusheng Huang, Yichuan Xu and Yang Zhang ${ }^{*}$ (i)
}

\begin{abstract}
Background: Postoperative delirium is a common complication following major surgeries, leading to a variety of adverse effects. However, there is a paucity of literatures studying the incidence and risk factors associated with delirium after primary elective total hip arthroplasty (THA) using a large-scale national database.

Methods: A retrospective database analysis was performed based on Nationwide Inpatient Sample (NIS) from 2009 to 2014. Patients who underwent primary elective THA were included. Patient demographics, preoperative comorbidities, length of hospital stay (LOS), total charges, in-hospital mortality, and major and minor perioperative complications were evaluated.

Results: A total of 388,424 primary elective THAs were obtained from the NIS database, and the general incidence of delirium after THA was $0.90 \%$. Patients with delirium after THA presented more preoperative comorbidities, longer LOS, extra hospital charges, and higher in-hospital mortality rate $(P<0.001)$. Delirium following THA was associated with major complications during hospitalization including acute renal failure and pneumonia. Preoperative risk factors associated with postoperative delirium included advanced age, alcohol or drug abuse, depression, neurological disorders, psychoses, fluid and electrolyte disorders, diabetes, weight loss, deficiency anemia, coagulopathy, hypertension, congestive heart failure, valvular disease, pulmonary circulation disorders, peripheral vascular disorders, and renal failure. Both female and obesity were detected to be protective factors.

Conclusions: The results of our study identified a relatively low incidence of delirium after primary elective THA, which is as reported in the NIS and not necessarily the surgical population as a whole. Postoperative delirium of THA was associated with increased preoperative comorbidities, LOS, total charges, in-hospital mortality, and major perioperative complications including acute renal failure and pneumonia. It is of benefit to study risk factors associated with postoperative delirium to moderate its consequences.
\end{abstract}

Keywords: Postoperative delirium, Total hip arthroplasty, Nationwide inpatient sample

\footnotetext{
*Correspondence: nfgjzy@126.com

${ }^{\dagger}$ Qinfeng Yang and Jian Wang contributed equally to this work.

Department of Orthopaedic Surgery, Division of Orthopaedics, Nanfang

Hospital, Southern Medical University, Guangzhou, 1838 Guangzhou Avenue,

Guangzhou 510515, Guangdong, China
}

(c) The Author(s). 2020 Open Access This article is licensed under a Creative Commons Attribution 4.0 International License, which permits use, sharing, adaptation, distribution and reproduction in any medium or format, as long as you give appropriate credit to the original author(s) and the source, provide a link to the Creative Commons licence, and indicate if changes were made. The images or other third party material in this article are included in the article's Creative Commons licence, unless indicated otherwise in a credit line to the material. If material is not included in the article's Creative Commons licence and your intended use is not permitted by statutory regulation or exceeds the permitted use, you will need to obtain permission directly from the copyright holder. To view a copy of this licence, visit http://creativecommons.org/licenses/by/4.0/. The Creative Commons Public Domain Dedication waiver (http://creativecommons.org/publicdomain/zero/1.0/) applies to the data made available in this article, unless otherwise stated in a credit line to the data. 


\section{Background}

Total hip arthroplasty (THA) remains one of the most successful procedures in alleviating pain and restoring function of the hip [1]. Currently, about 400,000 THAs are performed each year in the United States, which is expected to increase up to 572,000 by 2030 [2]. However, quite a few postoperative patients suffer from postoperative complications.

Postoperative delirium is one of the common complications after THA, resulting in heavy burdens on individuals and society [1]. Delirium is a clinical syndrome characterized by the disturbance of consciousness, cognitive function, or perception. It is regarded to be caused by maladaptation of the brain to the surgical stress [3, 4]. Postoperative delirium is a common complication in geriatric patients after major surgery $[5,6]$. The reported incidence of delirium after THA ranges from 5 to $17 \%$, which varies for many reasons, such as patient population, definition and diagnosis of delirium [1, 7-9]. It has become a heavy burden on healthcare resources because it delays discharge and increases medical costs $[1,7,9]$. About 2.4 million hospitalized elderly patients suffer from delirium and the annual cost ranges from $\$ 143$ billion to $\$ 152$ billion [10]. Besides, postoperative delirium has an adverse impact on patients, family members, and health care practitioners, as it had been shown to be associated with higher mortality, progressive functional impairment, longterm cognitive disorder and other complications [11-18].

In order to optimize postoperative outcomes and prevent complications, it is critical to identify preoperatively whether patients are at high risk of postoperative delirium $[1,19-21]$. Several risk factors associated with postoperative delirium had been reported in previous literatures, among which advanced age is the most frequently acknowledged [1, 9, 19-25]. Other risk factors, including a history of dementia or psychiatric illness, cognitive impairment, polypharmacy, postoperative electrolyte disorders, and diabetes, had also been identified $[1,9,20-25]$. However, currently there is a paucity of studies about the incidence and risk factors associated with postoperative delirium after primary elective THA based on large-scale national database analysis [7, 9, 20-25].

The purpose of this study was to investigate the incidence and risk factors associated with delirium after primary elective THA, based on a national database, with the hypothesis that postoperative delirium has a relatively lower incidence and numerous risk factors to highlight patient groups that might require preoperative optimization. The incidence, patient demographics, Charlson Comorbidity Index (CCI), length of stay (LOS), total charges, in-hospital mortality, major and minor perioperative complications and risk factors associated with postoperative delirium after THA were evaluated.

\section{Methods}

\section{Data source}

The Nationwide Inpatient Sample (NIS) database is part of the Healthcare Cost and Utilization Project, Agency for Healthcare Research and Quality, and was the data source for this study. In the United States, the NIS represents the largest all-payer database of hospital admissions. The NIS collects a stratified sample from more than 1000 hospitals, of approximately $20 \%$ of the hospitalizations in the United States each year [26]. The information, including patient demographics, LOS, total hospital charges, diagnostic and procedural codes from International Classification of Diseases (ninth revision) Clinical Modification (ICD-9-CM) were extracted from this database.

\section{Data collection}

Data was obtained from the NIS database from 2009 to 2014. Patients were identified according to ICD-9-CM procedural codes of THA (81.51). Given an inherent limitation that the information about who assessed these patients using which tools at which times was unavailable in NIS database. The diagnoses of delirium might be made by surgeons or physicians varied between hospitals. Hence, delirium only could be defined by ICD-9CM diagnostic codes based on prior studies. Patients with a diagnosis of delirium were defined by ICD-9-CM diagnostic codes and selected, including transient mental disorders, acute and subacute delirium (293, 293.0, 293.1, 293.8, 293.9, 293.81-84, 293.89), drug-induced delirium (292.81), and altered mental status (780.97) [11]. Patients who were less than 18 years of age, had a hip fracture, were non-elective admission, had osteomyelitis, or had pathologic fracture were excluded from this study.

The recruited cases were divided into two groups according to the occurrence of postoperative delirium. Patient demographics, including age, sex, and race, were evaluated. Outcome measures such as LOS, total charges during hospitalization, and in-hospital mortality were analyzed. Major and minor perioperative complications before discharge were searched from the database by ICD-9-CM diagnostic code. Major perioperative complications were defined as acute renal failure, death, myocardial infarction, pneumonia, pulmonary embolism, and stroke. Minor perioperative complications included deep vein thrombosis, hip dislocation, seroma/hematoma, and wound infection [7]. The included covariates were preoperative comorbidities only and did not include postoperative complications, given a numerical score according to the CCI. There were 17 comorbid conditions assigned with specific point values, where higher score means more comorbidities [27]. As comorbidity definitions in the NIS database vary slightly from the CCI, several 
modifications were made for analysis: A history of coronary heart disease or leukemia was omitted from the CCI score; liver disease got a weighted value of 2 points instead of 1 point for mild chronic liver disease and 3 points for moderate to severe liver disease [11]. Other comorbid conditions and their point values were: age (age $\leq 50$ yrs. $=1$, age $51-60$ yrs. $=2$, age $61-70$ yrs. $=3$, age $\geq 71$ yrs. $=4$ ), congestive heart failure (1), peripheral vascular disorders (1), neurological disorders (1), psychoses (2), chronic pulmonary disease (1), rheumatoid arthritis/collagen vascular diseases (1), peptic ulcer disease (1), diabetes without complications (1), diabetes with complications (2), paralysis (2), renal disease (2), lymphoma (2), liver disease (2), solid tumor without metastasis (2), metastatic cancer (6), and AIDS/HIV (6).

\section{Data analysis}

The statistical software, $\mathrm{R}$ version 3.5.3 was used to perform statistical analysis. Significant differences between two groups were determined by Wilcoxon rank test for continuous data and chi-square test for categorical data. Univariate and multivariate logistic regression models were constructed to assess the association of delirium with major and minor perioperative complications. To identify independent risk factors for postoperative delirium, binary logistic regression with the stepwise method was performed. All variables, including demographics, hospital characteristics, and preoperative comorbidities which were provided by the NIS were entered into the regression analysis (Table 1). Statistical significance was defined by an alpha level of $P \leq 0.001$ because of the large-scale sample volume, which has been utilized by other NIS-researches $[11,28]$.

\section{Results}

Incidence of postoperative delirium in patients undergoing primary elective THA

It was found that the incidence of postoperative delirium was gradually increasing from 2005 to 2008 (from 0.96 to $1.28 \%$ ) (Fig. 1), while annually decreasing from 2008 to 2014 (from 1.28 to $0.66 \%$ ) (Fig. 1). As the incidence clearly changes over time, we chose to focus on the data after break point (2009-2014), which was most current data with a smaller interval to limit heterogeneity.

A total of 388,424 THAs were identified in the NIS database from 2009 to 2014. Overall, there were 3481 cases of postoperative delirium with an incidence of 0.90\% (Table 2).

\section{Demographics of patients with postoperative delirium}

There was no significant difference of postoperative delirium incidence between two genders $(P=0.006)$. Patients suffered from postoperative delirium $(77 \mathrm{yrs}$.) were significantly older than those without postoperative delirium $(65$ yrs. $)(P<0.001)$. Consistently, patients older than 71 years accounted for a significant larger proportion in the postoperative delirium group $(\mathrm{P}<0.001)$ (Table 2). Meanwhile, postoperative delirium occurred more frequently in Whites $(P<0.001)$ (Table 2$)$.

\section{Adverse effects of postoperative delirium after primary elective THA}

Patients with postoperative delirium demonstrated significant greater CCI scores ( 4 vs. $3, P<0.001$ ), which as mentioned previously, represented more comorbidities. Not surprisingly, in-hospital mortality was increased from 0.13 to $0.81 \%$ with the presence of postoperative delirium $(P<0.001)$ (Table 2). The mean LOS of patients with delirium was longer than those without delirium (4 d vs. 3 d; $\mathrm{P}<0.001$ ) (Table 2). Consequently, postoperative delirium increased medical cost. There was an average increase of $\$ 9048$ in total hospital charges, with the presence of postoperative delirium $(\$ 56,984$ vs. $\$ 47,936$, $P<0.001$ ) (Table 2).

Those with delirium were more likely to have major perioperative complications including acute renal failure and pneumonia compared with patients without delirium $(\mathrm{P}<0.001)$ (Table 3). Postoperative delirium were found to be associated with overall major perioperative complications (odds ratio $[\mathrm{OR}]=2.59 ; 95 \%$ confidence interval $[\mathrm{CI}]=1.92-3.48)$, and specifically, acute renal failure $(\mathrm{OR}=1.95 ; \mathrm{CI}=1.47-2.59)$ and pneumonia $(\mathrm{OR}=$ 2.48; $\quad \mathrm{CI}=1.90-3.25)$. However, delirium was not

Table 1 Variables Entered into the Binary Logistic Regression Analysis

\begin{tabular}{ll}
\hline Variables Categories & Specific Variables \\
\hline Patient demographics & Age ( $\leq 60 \mathrm{yr}$ and $\geq 61$ yr), sex (male and female), race (White, Black, Hispanic, Asian or Pacific Islander, \\
& Native American and Other) \\
Hospital characteristics & $\begin{array}{l}\text { bed size of hospital (small, medium, large), teaching status of hospital (nonteaching, teaching), location } \\
\text { of hospital (rural, urban) }\end{array}$ \\
AlDS, alcohol abuse, deficiency anemia, rheumatoid arthritis/collagen vascular diseases, chronic blood loss \\
anemia, congestive heart failure, chronic pulmonary disease, coagulopathy, depression, diabetes (uncomplicated), \\
diabetes (with chronic complications), drug abuse, hypertension, hypothyroidism, liver disease, lymphoma, fluid \\
and electrolyte disorders, metastatic cancer, neurological disorders, obesity, paralysis, peripheral vascular disorders, \\
psychoses, pulmonary circulation disorders, renal failure, solid tumor without metastasis, peptic ulcer disease, \\
valvular disease, weight loss
\end{tabular}




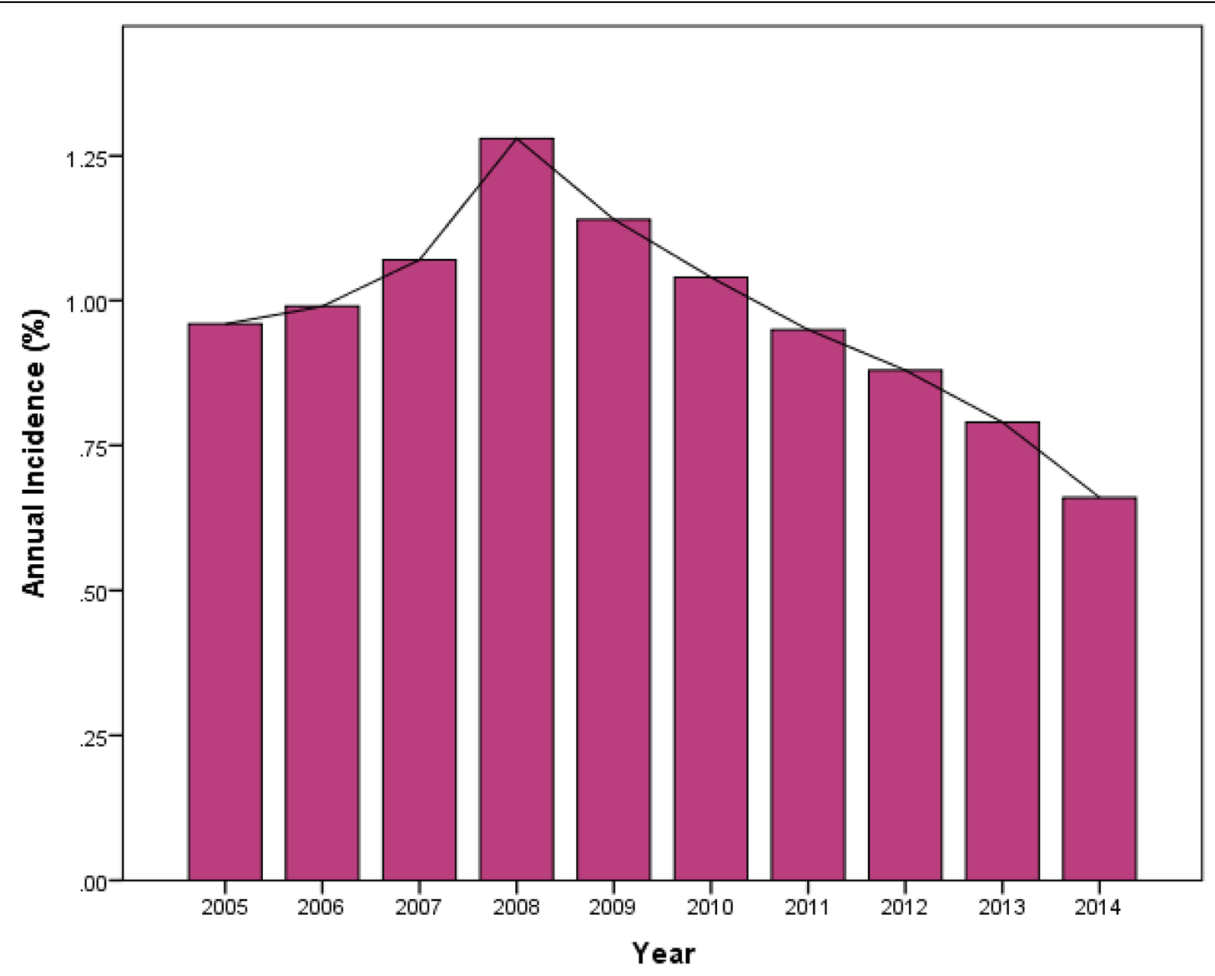

Fig. 1 Annual Incidence of Postoperative Delirium in Patients Undergoing Primary Elective THA

Table 2 Patient Characteristics and Outcomes of Delirium after Primary Elective THA (2009-2014)

\begin{tabular}{|c|c|c|c|}
\hline Parameter & No delirium & Delirium & P \\
\hline Total ( $n=$ count $)$ & 384,943 & 3481 & \\
\hline Total incidence (\%) & 0.90 & & \\
\hline Age (yrs.) & $65(57-74)$ & $77(69-83)$ & $<0.001$ \\
\hline \multicolumn{4}{|l|}{ Age group (\%) } \\
\hline$\leq 50$ & 11.01 & 2.15 & \multirow[t]{4}{*}{$<0.001$} \\
\hline $51-60$ & 23.80 & 7.07 & \\
\hline $61-70$ & 31.19 & 18.33 & \\
\hline$\geq 71$ & 34.00 & 72.45 & \\
\hline Sex (\% female) & 55.83 & 58.16 & 0.006 \\
\hline \multicolumn{4}{|l|}{ Race (\%) } \\
\hline White & 86.12 & 89.52 & \multirow[t]{6}{*}{$<0.001$} \\
\hline Black & 7.39 & 5.08 & \\
\hline Hispanic & 3.24 & 2.52 & \\
\hline Asian or Pacific Islander & 0.83 & 0.71 & \\
\hline Native American & 0.37 & 0.32 & \\
\hline Other & 2.06 & 1.84 & \\
\hline $\mathrm{CCl}^{\mathrm{a}}$ & $3(2-4)$ & $4(4-5)$ & $<0.001$ \\
\hline $\operatorname{LOS}^{b}(d)$ & $3(2-3)$ & $4(3-6)$ & $<0.001$ \\
\hline Total charges (\$) & $47,936(35,100.5-66,438)$ & $56,984(40,339-81,950)$ & $<0.001$ \\
\hline In-hospital mortality (\%) & 0.13 & 0.81 & $<0.001$ \\
\hline
\end{tabular}


Table 3 Complications Associated with Postoperative Delirium Following Primary Elective THA (2009-2014)

\begin{tabular}{|c|c|c|c|c|c|}
\hline Complication & No delirium & Delirium & $\mathrm{P}$ & Odds Ratio & 95\% Confidence Interva \\
\hline \multicolumn{6}{|l|}{ Major } \\
\hline Acute renal failure & $8342(2.17 \%)$ & $383(11 \%)$ & $<0.001$ & 1.95 & $1.47-2.59$ \\
\hline Death & $490(0.13 \%)$ & $28(0.81 \%)$ & 0.08 & 1.43 & $0.96-2.13$ \\
\hline Myocardial infarction & $74(0.02 \%)$ & $6(0.17 \%)$ & 0.07 & 2.20 & $0.93-5.19$ \\
\hline Pneumonia & $1904(0.49 \%)$ & $127(3.65 \%)$ & $<0.001$ & 2.48 & $1.90-3.25$ \\
\hline Pulmonary embolism & $345(0.09 \%)$ & $8(0.23 \%)$ & 0.42 & 0.74 & $0.35-1.55$ \\
\hline Stroke & $2734(0.71 \%)$ & $102(2.93 \%)$ & 0.003 & 1.62 & $1.18-2.21$ \\
\hline Any major complication ${ }^{a}$ & $12,958(3.37 \%)$ & $567(16.3 \%)$ & $<0.001$ & 2.59 & $1.92-3.48$ \\
\hline \multicolumn{6}{|l|}{ Minor } \\
\hline Deep vein thrombosis & $646(0.17 \%)$ & $21(0.6 \%)$ & 0.66 & 0.83 & $0.36-1.93$ \\
\hline Dislocation & $857(0.22 \%)$ & $30(0.86 \%)$ & 0.56 & 1.29 & $0.55-3.00$ \\
\hline Seroma/hematoma & $1010(0.26 \%)$ & $48(1.38 \%)$ & 0.41 & 1.39 & $0.63-3.03$ \\
\hline Wound infection & $379(0.1 \%)$ & $22(0.63 \%)$ & 0.35 & 1.46 & $0.66-3.21$ \\
\hline Any minor complication ${ }^{b}$ & $2790(0.72 \%)$ & $113(3.25 \%)$ & 0.03 & 2.44 & $1.08-5.50$ \\
\hline
\end{tabular}

Any major complication $^{\mathrm{a}}$ or minor complication ${ }^{\mathrm{b}}$ : patients with more than one complication are counted only once

Table 4 Risk Factors for Postoperative Delirium (2009-2014)

\begin{tabular}{|c|c|c|c|}
\hline Variable & Odds Ratio & 95\% Confidence Interval & $P$ \\
\hline Age $\geq 61 \mathrm{yr}$ & 4.27 & $3.76-4.86$ & $<0.001$ \\
\hline Female & 0.88 & $0.82-0.95$ & $<0.001$ \\
\hline Alcohol abuse & 1.85 & $1.51-2.27$ & $<0.001$ \\
\hline Deficiency anemia & 1.32 & $1.21-1.45$ & $<0.001$ \\
\hline Chronic blood loss anemia & 1.43 & $1.15-1.79$ & 0.002 \\
\hline Congestive heart failure & 1.62 & $1.42-1.86$ & $<0.001$ \\
\hline Coagulopathy & 1.43 & $1.22-1.67$ & $<0.001$ \\
\hline Depression & 1.39 & $1.26-1.53$ & $<0.001$ \\
\hline Diabetes, uncomplicated & 1.27 & $1.15-1.39$ & $<0.001$ \\
\hline Diabetes with chronic complications & 1.55 & $1.25-1.92$ & $<0.001$ \\
\hline Drug abuse & 2.53 & $1.90-3.36$ & $<0.001$ \\
\hline Hypertension & 1.23 & $1.13-1.34$ & $<0.001$ \\
\hline Lymphoma & 1.58 & $1.04-2.41$ & 0.03 \\
\hline Fluid and electrolyte disorders & 2.58 & $2.37-2.81$ & $<0.001$ \\
\hline Metastatic cancer & 1.94 & $1.27-2.96$ & 0.002 \\
\hline Other neurological disorders & 9.43 & $8.69-10.24$ & $<0.001$ \\
\hline Obesity & 0.72 & $0.64-0.81$ & $<0.001$ \\
\hline Peripheral vascular disorders & 1.33 & $1.14-1.55$ & $<0.001$ \\
\hline Psychoses & 1.82 & $1.52-2.17$ & $<0.001$ \\
\hline Pulmonary circulation disorders & 1.61 & $1.30-2.00$ & $<0.001$ \\
\hline Renal failure & 1.40 & $1.24-1.58$ & $<0.001$ \\
\hline Valvular disease & 1.40 & $1.22-1.60$ & $<0.001$ \\
\hline Weight loss & 1.76 & $1.41-2.20$ & $<0.001$ \\
\hline
\end{tabular}


associated with any minor perioperative complications (Table 3).

\section{Risk factors associated with postoperative delirium after primary elective THA}

Logistic regression analysis was applied to investigate preoperative risk factors associated with postoperative delirium (Table 4), and the following indicators were identified: advanced age ( $\geq 61$ years, odds ratio $[\mathrm{OR}]=4.27$; 95\% confidence interval $[\mathrm{CI}]=3.76-4.86 ; P<0.001)$, alcohol abuse $(\mathrm{OR}=1.85 ; \mathrm{CI}=1.51-2.27)$, deficiency anemia $(\mathrm{OR}=1.32 ; \mathrm{CI}=1.21-1.45)$, congestive heart failure $(\mathrm{OR}=$ $1.62 ; \mathrm{CI}=1.42-1.86)$, coagulopathy $(\mathrm{OR}=1.43 ; \mathrm{CI}=1.22$ $1.67)$, depression $(\mathrm{OR}=1.39 ; \mathrm{CI}=1.26-1.53)$, uncomplicated diabetes $(\mathrm{OR}=1.27 ; \mathrm{CI}=1.15-1.39)$, diabetes with chronic complications $(\mathrm{OR}=1.55 ; \mathrm{CI}=1.25-1.92)$, drug abuse $(\mathrm{OR}=2.53 ; \mathrm{CI}=1.90-3.36)$, hypertension $(\mathrm{OR}=$ 1.23; $\mathrm{CI}=1.13-1.34)$, fluid and electrolyte disorders $(\mathrm{OR}=$ 2.58; $\mathrm{CI}=2.37-2.81)$, neurological disorders $(\mathrm{OR}=9.43$; $\mathrm{CI}=8.69-10.24)$, peripheral vascular disorders $(\mathrm{OR}=1.33$; $\mathrm{CI}=1.14-1.55)$, psychoses $\quad(\mathrm{OR}=1.82 ; \mathrm{CI}=1.52-2.17)$, pulmonary circulation disorders $(\mathrm{OR}=1.61 ; \mathrm{CI}=1.30$ 2.00), renal failure $(\mathrm{OR}=1.40 ; \mathrm{CI}=1.24-1.58)$, valvular disease $(\mathrm{OR}=1.40 ; \mathrm{CI}=1.22-1.60)$, and weight loss $(\mathrm{OR}=$ $1.76 ; \mathrm{CI}=1.41-2.20)$. Interestingly, there were two protective factors for postoperative delirium including female $(\mathrm{OR}=0.88 ; \mathrm{CI}=0.82-0.95 ; P<0.001)$ and obesity $(\mathrm{OR}=$ $0.72 ; \mathrm{CI}=0.64-0.81 ; P<0.001)$.

\section{Discussion}

This study has provided a large-scale and healtheconomic analysis of postoperative delirium after primary elective THA. It is worth mentioning that this data represented the NIS and may not be necessarily taken to represent the surgical population as a whole. From the year 2005 to 2008, the incidence of postoperative delirium was increasing annually from 0.96 to $1.28 \%$. Then, the incidence of postoperative delirium decreased gradually to $0.66 \%$ in 2014 (Fig. 1). Interestingly, this trend had never been reported in previous studies. Although there was no change of the definition of delirium over this decade, according to ICD-9-CM, the diagnosis of delirium may vary among institutions [11]. One possible explanation accounting for the observed increase in the incidence of delirium following THA prior 2008, to some degree, might be related to growing awareness of this complication by hospital coders [29]. Another possible explanation for this trend may be that the number of THA performed was increased with aging of population (Fig. 2), however, the lack of recognition and medical interventions, or the immature types of anesthesia and protocols of relieving pain likely led to a higher incidence of postoperative delirium [11,30]. Then postoperative delirium received more and more attention and this trend was reversed after 2008. We identified an overall incidence of $0.90 \%$ after THA procedures, which is much lower compared with the previous studies

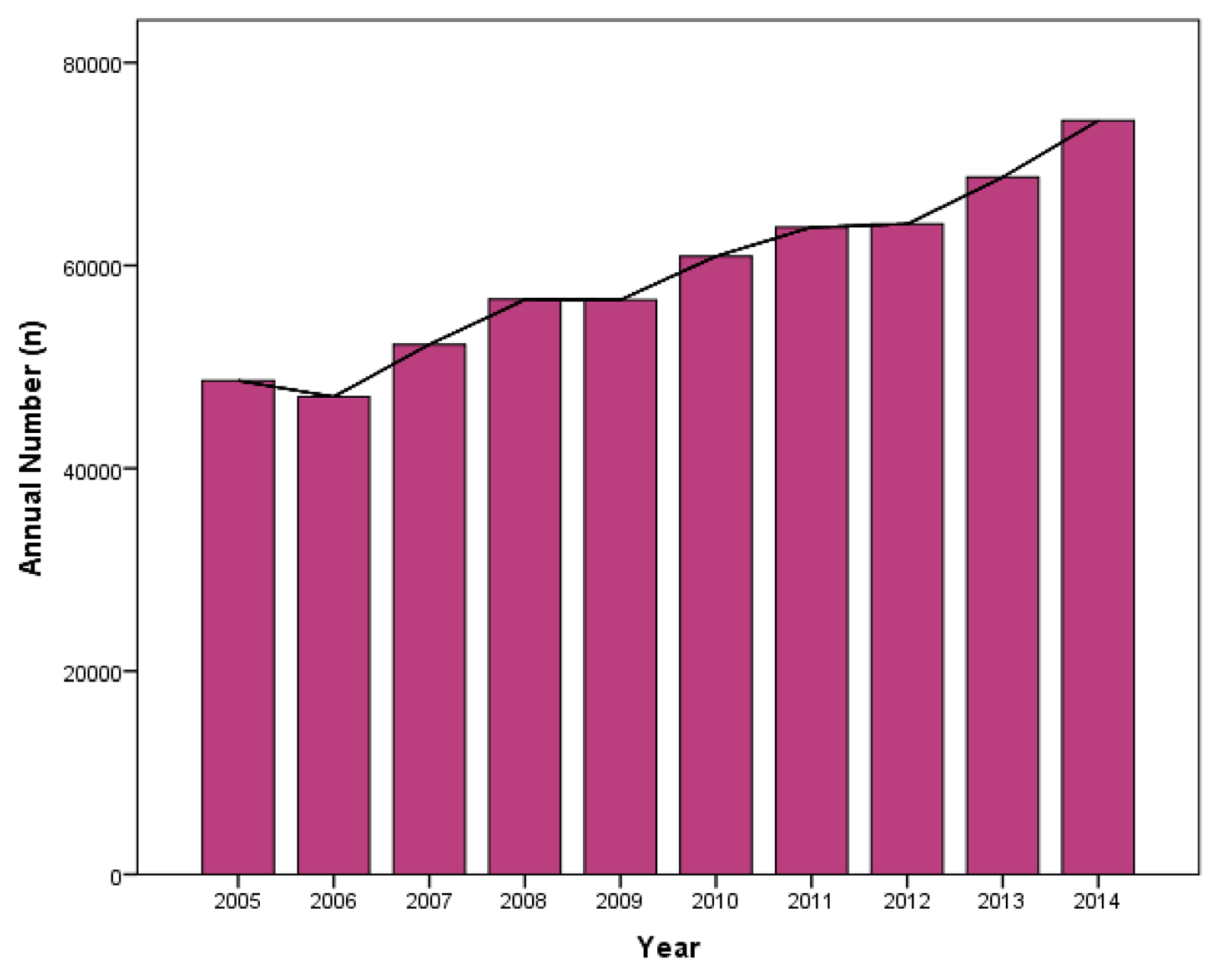

Fig. 2 Annual Number of Patients Undergoing Primary Elective THA 
ranging from 5 to $17 \%$ [1, 7-9]. There are several possible reasons accounting for this obvious difference. First, previous literatures observed small-scale and selected senior patients, resulting in a higher incidence [11]. Second, the definition and diagnosis of delirium varied among institutions according to the criteria utilized may also contributed to the difference. When the ICD classification is compared with the psychiatricbased Diagnostic and Statistical Manual (DSM) classification, the former is felt to be much more restrictive and less inclusive than the latter [11, 31, 32]. Third, the limitation of NIS database, such as only providing inhospital delirium, high specificity (low false-positive rate), and low sensitivity (high false-negative rate) may lead to underestimating the incidence [29, 31]. Forth, the actual manifestations of delirium, such as disorganized thinking, alteration of consciousness, cognitive defects, and perceptual disturbances could not be included in NIS because they are not part of an ICD-9-CM diagnostic codes. Furthermore, it is also likely that the hypoactive form of delirium was under-diagnosed [32].

In terms of demographics, patients suffered from postoperative delirium were significantly older than those without. This was highly consistent with previous studies which had identified advanced age as a common independent predictor of postoperative delirium $[1,9,20-$ 25]. Interestingly, there was significant difference of race distribution between the two groups, indicating a racial difference in occurrence of postoperative delirium. Our study found that Whites patients occupying a larger proportion in the postoperative delirium group. This is consistent with the previous report that Whites patients undergoing general or orthopedic surgery were more likely to develop postoperative delirium [33]. However, very few studies have focused on racial difference in postoperative delirium.

The CCI score of patients with postoperative delirium was significantly higher. This is reasonable as higher CCI score means relatively worse healthy condition before surgery, and may increase postoperative complications including delirium. Postoperative delirium has been reported to increase hospitalization duration, medical cost, and mortality $[1,7,9,11]$. Similar findings were observed in our study. With the presence of postoperative delirium, the average LOS was 1 day longer and the total hospital charge was $\$ 9048$ more per admission, which may be due to that these patients need additional nursing instructions and rehabilitation [12, 34]. Further, postoperative delirium may be associated with other postoperative complications [35], including acute renal failure and pneumonia, which was consistent with the observation by Aziz et al. [7].

A systematic review on postoperative delirium after total joint arthroplasty suggested that pre-screening and risk stratification is essential to improve outcomes [1]. Thus, in order to prevent postoperative delirium, it is critical to understand the risk factors before surgery. Logistic regression was applied and the results were consistent with previous publications [1, 9, 20-25]. Interestingly, female and obesity were found to be protective factors. The reasons for these remains unclear but likely multifactorial. There are several prior findings probably relevant and worth discussing [36-38]. Melatonin, a hormone secreted by the pineal gland, has been found to be relevant to female hormone and obesity [36, 37]. Prior study reported that alterations in the metabolism or a disturbed circadian pattern of melatonin may play a role in the development of delirium [38]. The use of melatonin for the prevention of delirium indicates that the complex relationships among female, obesity, melatonin, and postoperative delirium will need further study [36].

Aziz et al. had performed a study of postoperative delirium using the same database from 2000 to 2009 [7]. They also found that delirium was associated with postoperative complications including seroma/hematoma, and wound infection, which was not observed in our study. The possible explanation may be that they studied both total and partial hip arthroplasty, while only primary elective total hip arthroplasty was included in our study. Meanwhile, data from different period (2009-2014 vs. 2000-2009) may also contribute to this inconsistency.

Several limitations exist in utilizing the NIS database. First, information of each patient is only recorded before discharge, meaning any complication that occurs after discharge will not be included in the NIS database. This limitation might contribute to the lower incidence of postoperative delirium as only early period medical records were analyzed [11]. Second, only risk factors recorded in the NIS database could be analyzed. There are other known risk factors that were not available in the NIS database, such as type of anaesthesia, commonly used perioperative medications (opioids, benzodiazepines, and ketamine), sedation during anesthesia recovery, vision impairment, functional impairment, and so on $[11,22,25,30]$. Third, information about who assessed patients with delirium using which tools at which times was unavailable in NIS database. The diagnoses of delirium might be made by surgeons or physicians varied among hospitals. Hence, delirium only could be defined by ICD-9-CM diagnostic codes based on prior studies [11]. Furthermore, as with any large database, there may be discrepancy or misclassification in coding and documentation. Thus, administrative data tend to have high specificity (low falsepositive rate) but low sensitivity (high false-negative rate) in identifying adverse events, which may also underestimate the incidence of postoperative delirium following THA [11, 29, 31]. 


\section{Conclusions}

Postoperative delirium is a common complication typically occurring in the elderly after primary elective THA, with an overall incidence of $0.90 \%$. The annual incidence of postoperative delirium was increasing gradually from 2005 to 2008 while decreasing from 2008 to 2014. Numerous preoperative risk factors have been identified in this study including advanced age ( $\geq 61 \mathrm{yrs}$.), alcohol and drug abuse, a history of neurological and psychiatric diseases, fluid and electrolyte disorders, complicated or uncomplicated diabetes, weight loss, deficiency anemia, coagulopathy, hypertension, congestive heart failure, valvular disease, pulmonary circulation disorders, peripheral vascular disorders and renal failure. Both female and obesity, however, are protective factors. The occurrence of delirium after THA was associated with an increased LOS, extra total hospital charges, higher inpatient mortality and major perioperative complications (acute renal failure and pneumonia), but not minor complications.

\section{Abbreviations}

THA: Total hip arthroplasty; NIS: Nationwide Inpatient Sample; LOS: Length of stay; CCl: Charlson Comorbidity Index; OR: Odds ratio; Cl: Confidence interval

\section{Acknowledgements}

Not applicable.

\section{Authors' contributions}

QY and JW contributed to the study design, data acquisition and analysis, interpretation of results, and writing and revising the manuscript. $\mathrm{XH}$ contributed to the study design, interpretation of results, and reviewing the manuscript. YX contributed to data acquisition, data analysis, and reviewing of the manuscript. $Y Z$ contributed to the study design, interpretation of results, and reviewing the manuscript. All authors read and approved the final manuscript.

\section{Funding}

This research did not receive any specific grant from funding agencies in the public, commercial, or not-for-profit sectors.

\section{Availability of data and materials}

This study is based on data provided by Nationwide Inpatient Sample (NIS) database, part of the Healthcare Cost and Utilization Project, Agency for Healthcare Research and Quality. The NIS database is a large publicly available all-payer inpatient care database in the United States. Therefore, individual or grouped data cannot be shared by the authors.

\section{Ethics approval and consent to participate}

This article does not contain any studies with human participants or animals performed by any of the authors. This observational study was deemed exempt by the institutional review board that waived the need for consent because it used deidentified publicly available data.

\section{Consent for publication}

Not applicable.

\section{Competing interests}

The authors declare that they have no competing interest.
Received: 3 March 2020 Accepted: 18 June 2020

Published online: 01 July 2020

\section{References}

1. Bin Abd Razak HR, Yung WY. Postoperative delirium in patients undergoing Total joint Arthroplasty: a systematic review. J Arthroplasty. 2015;30:1414-7.

2. Kurtz $S$, Ong K, Lau E, Mowat F, Halpern M. Projections of primary and revision hip and knee arthroplasty in the United States from 2005 to 2030. J Bone Joint Surg Am. 2007:89:780-5.

3. Rai D, Garg RK, Malhotra HS, Verma R, Jain A, Tiwari SC, et al. Acute confusional state/delirium: An etiological and prognostic evaluation. Ann Indian Acad Neurol. 2014;17:30-4.

4. Choi YH, Kim DH, Kim TY, Lim TW, Kim SW, Yoo JH. Early postoperative delirium after hemiarthroplasty in elderly patients aged over 70 years with displaced femoral neck fracture. Clin Interv Aging. 2017;12:1835-42.

5. Schmitt EM, Marcantonio ER, Alsop DC, Jones RN, Rogers SO Jr, Fong TG, et al. Novel risk markers and long-term outcomes of delirium: the successful aging after elective surgery (SAGES) study design and methods. J Am Med Dir Assoc. 2012;13:818.e1-10.

6. Hong N, Park JY. The motoric types of delirium and estimated blood loss during perioperative period in orthopedic elderly patients. Biomed Res Int. 2018;2018:9812041.

7. Aziz KT, Best MJ, Naseer Z, Skolasky RL, Ponnusamy KE, Sterling RS, et al. The association of delirium with perioperative complications in primary elective total hip arthroplasty. Clin Orthop Surg. 2018;10:286-91.

8. Bosmak FS, Gibim PT, Guimarães S, Ammirati AL. Incidence of delirium in postoperative patients treated with total knee and hip arthroplasty. Rev Assoc Med Bras. 2017:63:248-51.

9. Scott JE, Mathias JL, Kneebone AC. Incidence of delirium following total joint replacement in older adults: a meta-analysis. Gen Hosp Psychiatry. 2015;37:223-9.

10. Leslie DL, Marcantonio ER, Zhang Y, Leo-Summers L, Inouye SK. One-year health care costs associated with delirium in the elderly population. Arch Intern Med. 2008;168:27-32.

11. Fineberg SJ, Nandyala SV, Marquez-Lara A, Oglesby M, Patel AA, Singh K. Incidence and risk factors for postoperative delirium after lumbar spine surgery. Spine. 2013;38:1790-6.

12. Brauer C, Morrison RS, Silberzweig SB, Siu AL. The cause of delirium in patients with hip fracture. Arch Intern Med. 2000;160:1856-60.

13. Fong TG, Jones RN, Marcantonio ER, Tommet D, Gross AL, Habtemariam D, et al. Adverse outcomes after hospitalization and delirium in persons with alzheimer disease. Ann Intern Med. 2012;156:848-56 W296.

14. Anderson $\mathrm{CP}, \mathrm{Ngo} \mathrm{LH}$, Marcantonio ER. Complications in post-acute care are associated with persistent delirium. J Am Geriatr Soc. 2012;60:1122-7.

15. Marcantonio ER, Flacker JM, Wright RJ, Resnick NM. Reducing delirium after hip fracture: a randomized trial. J Am Geriatr Soc. 2001;49:516-22.

16. Jankowski CJ, Trenerry MR, Cook DJ, Buenvenida SL, Stevens SR, Schroeder $D R$, et al. Cognitive and functional predictors and sequelae of postoperative delirium in elderly patients undergoing elective joint arthroplasty. Anesth Analg. 2011;112:1186-93

17. Saczynski JS, Marcantonio ER, Quach L, Fong TG, Gross A, Inouye SK, et al. Cognitive trajectories after postoperative delirium. N Engl J Med. 2012;367: 30-9.

18. Gottesman RF, Grega MA, Bailey MM, Pham LD, Zeger SL, Baumgartner WA, et al. Delirium after coronary artery bypass graft surgery and late mortality. Ann Neurol. 2010;67:338-44.

19. Nandi S, Harvey WF, Saillant J, Kazakin A, Talmo C, Bono J. Pharmacologic risk factors for post-operative delirium in total joint arthroplasty patients: a case-control study. J Arthroplasty. 2014;29:268-71.

20. Rizk P, Morris W, Oladeji P, Huo M. Review of postoperative delirium in geriatric patients undergoing hip surgery. Geriatr Orthop Surg Rehabil. 2016; 7:100-5.

21. Kalisvaart KJ, Vreeswijk R, de Jonghe JF, van der Ploeg T, van Gool WA, Eikelenboom P. Risk factors and prediction of postoperative delirium in elderly hip-surgery patients: implementation and validation of a medical risk factor model. J Am Geriatr Soc. 2006:54:817-22.

22. Oh ES, Li M, Fafowora TM, Inouye SK, Chen CH, Rosman LM, et al. Preoperative risk factors for postoperative delirium following hip fracture repair: a systematic review. Int J Geriatr Psychiatry. 2015;30:900-10. 
23. Wang LH, Xu DJ, Wei XJ, Chang HT, Xu GH. Electrolyte disorders and aging: risk factors for delirium in patients undergoing orthopedic surgeries. BMC Psychiatry. 2016;16:418.

24. de Jong L, van Rijckevorsel VAJIM, Raats JW, Klem TMAL, Kuijper TM, Roukema GR. Delirium after hip hemiarthroplasty for proximal femoral fractures in elderly patients: risk factors and clinical outcomes. Clin Interv Aging. 2019;14:427-35.

25. Huang J, Sprung J, Weingarten TN. Delirium following total joint replacement surgery. Bosn J Basic Med Sci. 2019;19:81-5.

26. Newman JM, Sodhi N, Dalton SE, Khlopas A, Newman RP, Higuera CA, et al. Does Parkinson disease increase the risk of perioperative complications after total hip arthroplasty? A nationwide database study. J Arthroplasty. 2018;33: S162-6.

27. Charlson ME, Charlson RE, Peterson JC, Marinopoulos SS, Briggs WM, Hollenberg JP. The Charlson comorbidity index is adapted to predict costs of chronic disease in primary care patients. J Clin Epidemiol. 2008;61:1234-40.

28. Ma Y, Passias P, Gaber-Baylis LK, Girardi FP, Memtsoudis SG. Comparative inhospital morbidity and mortality after revision versus primary thoracic and lumbar spine fusion. Spine J. 2010;10:881-9.

29. Menendez ME, Ring D, Barnes CL. Inpatient dislocation after primary Total hip Arthroplasty. J Arthroplast. 2016;31:2889-93.

30. Weinstein SM, Poultsides L, Baaklini LR, Mörwald EE, Cozowicz C, Saleh JN, et al. Postoperative delirium in total knee and hip arthroplasty patients: a study of perioperative modifiable risk factors. Br J Anaesth. 2018;120:9991008.

31. Bozic KJ, Bashyal RK, Anthony SG, Chiu V, Shulman B, Rubash HE. Is administratively coded comorbidity and complication data in total joint arthroplasty valid? Clin Orthop Relat Res. 2013;471:201-5.

32. Lin RY, Heacock LC, Fogel JF. Drug-induced, dementia-associated and nondementia, non-drug delirium hospitalizations in the United States, 19982005: an analysis of the National Inpatient Sample. Drugs Aging. 2010;27: 51-61.

33. Brooks Carthon JM, Jarrín O, Sloane D, Kutney-Lee A. Variations in postoperative complications across race, ethnicity and sex among older adults. J Am Geriatr Soc. 2013;61:1499-507.

34. Demeure MJ, Fain MJ. The elderly surgical patient and postoperative delirium. J Am Coll Surg. 2006;203:752-7.

35. Anderson CP, Ngo LH, Marcantonio ER. Complications in postacute care are associated with persistent delirium. J Am Geriatr Soc. 2012;60:1122-7.

36. Campbell AM, Axon DR, Martin JR, Slack MK, Mollon L, Lee JK. Melatonin for the prevention of postoperative delirium in older adults: a systematic review and meta-analysis. BMC Geriatr. 2019;19:272

37. Chojnacki C, Walecka-Kapica E, Błońska A, Winczyk K, Stępień A, Chojnacki J. Serotonin and melatonin secretion in postmenopausal women with eating disorders. Endokrynol Pol. 2016;67:299-304.

38. de Jonghe A, van Munster BC, van Oosten HE, Goslings JC, Kloen P, van Rees $C$, et al. The effects of melatonin versus placebo on delirium in hip fracture patients: study protocol of a randomised, placebo-controlled, double blind trial. BMC Geriatr. 2011;11:34.

\section{Publisher's Note}

Springer Nature remains neutral with regard to jurisdictional claims in published maps and institutional affiliations.

Ready to submit your research? Choose BMC and benefit from:

- fast, convenient online submission

- thorough peer review by experienced researchers in your field

- rapid publication on acceptance

- support for research data, including large and complex data types

- gold Open Access which fosters wider collaboration and increased citations

- maximum visibility for your research: over $100 \mathrm{M}$ website views per year

At $\mathrm{BMC}$, research is always in progress.

Learn more biomedcentral.com/submissions 